\title{
EQUITY AND THE GLOBAL POLICY ON CLIMATE CHANGE: A LAW AND ECONOMIC PERSPECTIVE
}

\author{
Andri G.Wibisana ${ }^{1}$
}

\begin{abstract}
The opponents of the global commitment to reduce greenhouse gases (GHGs) emissions seem to have shifted their arguments from the one emphasising on the issue of uncertainty to the one focusing on the economic burdens disproportionately placed on the current generation in general, and some developed countries in particular. Inevitably, the issue of equity becomes of highly importance in the recent climate policy debates.

This paper attempts to analyze the implementation of equity principles, i.e. intergenerational and intragenerational equity, in the global climate policy. In doing so, it will first briefly outline some prominent economic appraisals on the impacts of climate change. Afterwards, some proposals to incorporate equity into the economic appraisals will be analyzed. Emphasizing on the concepts of equity, this paper will finally offer some recommendations for post-Kyoto negotiations.
\end{abstract}

Keywords: historical emissions, per capita emissions, equity, discount rate, common-but-differentiated responsibility.

\section{Introduction}

For several decades, climate change has been considered one of major threats to humans and the global environment. It has been argued that humans are already experiencing the changing climate, at least in the form of an increase in the average surface temperature of the Earth, referred to as global warming or the greenhouse effect. If climate change continues at an increasing, or even at the same rate, it is very likely to be followed by various severe impacts, ranging from hotter and longer summers, to the melting of the polar ice sheets and the increased sea level. Although such a change might only gradually occur over decades or centuries, which could of course give more time for humans to make adaptations, some authors, such as Alley, have put forward the possibility of non-linear climate change, referred to as the abrupt climate change, in which the climate very rapidly shifts from one equilibrium to another. The impacts of such an abrupt change could be devastating for humans and the environment. ${ }^{2}$

\footnotetext{
${ }^{1}$ The author is lecturer of environmental law at Faculty of Law, Universitas Indonesia. SH from UI (1998), LLM from Utrect University (2002), and Dr. from Maastricht University (2008). He can be reached at andri.gunawan@ui.ac.id and mragw@yahoo.com.

${ }^{2}$ R.B. Alley, 2004, "Abrupt Climate Change", Scientific American, November 2004, pp. 62-69. The Synthesis Report of the Third Assessment Report (TAR) of the IPCC (2001) summarizes several possible impacts of climate change on human health, ecosystem, agriculture, water resource, and market sectors.
} 
Concerns about the impacts of climate change have increased the pressure on policy makers to take immadiate and concrete actions. However, despite such a growing pressure, some countries, led by the USA, still refuse to ratify the Kyoto Protocol, the only global arrangement that is currently available to deal with climate change. There are, at least, three reasons put forward against any binding commitment to abate the current emissions of greenhouse gases (GHGs). First, it is argued that climate change is still full of uncertainties related not only to the science of climate change, but also to some impacts considered to have low probability but high consequences. Due to such uncertainties, various economic studies have concluded that early emissions abatement in general and the Kyoto Protocol in particular are, indeed, economically inefficient. Mendelsohn, for example, argues that at this moment, the optimal solution to deal with climate change is to collect relevant information about climate change and its causes and impacts. According to Mendelsohn's view, GHGs reduction is, thus, not an optimal solution. In this view, the global policy on climate change should follow the "learn then act" approach: collecting more solid information to resolve uncertainty about climate change, followed by setting up measures that are suitable with the available information. ${ }^{3}$

Second, the Kyoto Protocol is economically indefensible because it requires costs that are much higher than the benefits it could offer. In this regard, Nordhaus and Boyer, in their widely cited book, conclude that the costs of meeting Kyoto commitments far outweigh the impacts of climate change. The authors estimate that global losses from climate change could be between 1.5 to $1.9 \%$ of the Gross World Product (GWP). ${ }^{4}$ Based on such an estimate, they argue that the optimal climate policy will require a $4.8 \%$ reduction be-

Those impacts are the consequences of linear climate change, which are likely to occur if no actions are taken by the current generation to curb their GHGs emissions. See: R. Watson and the Core Writing Team (eds.), 2001, Climate Change 2001-Synthesis Report: Contribution of Working Groups I, II, and III to the Third Assessment Report of the Intergovernmental Panel on Climate Change (Cambridge: Cambridge University Press), pp. 69-74. In addition to those impacts, the IPCC also predicts various possible impacts that have low probability to occur but are potentially catastrophic. Such impacts are referred to as the "large-scale singularities" or events with low probability and high consequences. These impacts include the shutdown of the Thermohaline Circulation (THC), which impacts could reduce the average temperature currently experienced by Europe and North Atlantic regions by about $10^{\circ} \mathrm{C}$, and the partial or complete collapse of the West Antarctic Ice Sheet (WAIS) and Greenland Ice Sheet (GIS), which impacts could raise the sea level up to 7 meters. See: J.B. Smith, et al. (2001), "Vulnerability to Climate Change and Reasons for Concern: A Synthesis", in: J.J. McCarthy, et al. (eds.), Climate Change 2001: Impacts, Adaptation, Vulnerability. Contribution of Working Group II to the Third Assessment Report of the Intergovernmental Panel on Climate Change (Cambridge: Cambridge University Press, 2001), pp. 946-947.

${ }^{3}$ R. Mendelsohn, 2004, “Perspective Paper 1.1”, in B. Lomborg (ed.), Global Crises, Global Solutions (Cambridge: Cambridge University Press), pp. 45-48. Similar opinion is also shared by Goklany, who basically argues that although there is a risk that climate change will create irreversible damage to humans and the environment, there is also a risk that emissions reduction will be unnecessary and expensive, and hence, will be irreversible for the economy. Taking into account a "balanced view" for those possible outcomes, Goklany concludes that early emissions reduction is not a wise and optimal solution. According to the author, the most sensible policy is the one that places a higher priority on the reductions of poverty and malnutrition, more real problems faced by the world today, and to improve adaptation efforts in order to reduce vulnerability to climate change impacts. I.M. Goklany, 2000, "Applying the Precautionary Principle to Global Warming", Policy Study No. 158, Center for the Study of American Business, November 2000, pp. 21-25.

${ }^{4}$ W.D. Nordhaus and J. Boyer, 2000, Warming the World: Economic Models of Global Warming (Cambridge, Ma: MIT Press), p. 91. 
low the Business as Usual (BAU) level in 2005, reaching a $10.5 \%$ reduction in 2100 . The optimal carbon tax is set up at 9.13US\$/tC in 2005, which will increase up to $12.71 \mathrm{US} \$ / \mathrm{tC}$ in 2015 and 67US\$/tC in $2100 .{ }^{5}$ The Kyoto Protocol, in contrast, will impose a carbon tax of $34.52 \mathrm{US} \$ / \mathrm{tC}$ in 2015 , under the possibility of emission trading among Annex I countries. ${ }^{6}$ Therefore, so Nordhaus and Boyer conclude, the Kyoto Protocol "has no economic or environmental rationale...Nor does it bear any relation to an economically oriented strategy that would balance the costs and benefits of greenhouse-gas reductions".?

Third, the Kyoto Protocol has also been refused because it disproportionately obliges some countries, i.e. developed countries, to cut their GHGs emissions, while allowing other major polluting countries, i.e. developing countries, to continue their increasing GHGs emissions. This is an argument used by George Bush Jr., to refuse the Kyoto Protocol. Bush, as cited by Blanchard and Perkaus, argues that the Protocol should be rejected because it excludes $80 \%$ of the world from the obligation to cut emissions. ${ }^{8}$ It is for this reason that Bush considers that the Protocol will disadvantage the US economy. As quoted by Henson, Bush argues "I told the world I thought that Kyoto was a lousy deal for America".9

The critiques above could be clustered into two types of arguments. While the first critique has rested on the economics of decision making under uncertainty, the last two critiques have particularly focused on the costs and benefits of meeting the Kyoto commitments. Although the importance of the former type of arguments should never be overlooked, this paper will, however, be devoted to analyse the latter type of arguments. ${ }^{10}$

In particular, this paper attempts to analyse the role of equity principles in shaping the debates over climate change policy. In doing so, this paper will first analyse the relationship between the principle of intergenerational equity and the use of discount rate in the economic appraisal of the impacts of climate change. Afterwards, the principle of intragenerational equity will also be discussed, especially with respect to the cross-regions aggregation of climate change impacts. In this way, this paper attempts to indicate how those two equity principles might come to an argument that is different from the conclusions of some economists mentioned above.

${ }^{5}$ Ibid., at $133-137$.

${ }^{6}$ Ibid., at 155.

${ }^{7}$ Ibid., at 177

${ }^{8}$ O. Blanchard and J.F. Perkaus, “Does the Bush Administration's Climate Policy Mean Climate Protection?",Energy Policy, Vol. 32, 2004, p. 1992.

${ }^{9}$ R. Henson, The Rough Guide to Climate Change: the Symptoms, the Science, and the Solutions (London: Rough Guides, Ltd, 2006), p. 274.

${ }^{10}$ There are some economists who have argued that early emissions abatement is justifiable based on the economics of decision making under uncertainty. In justifying the early abatement, economists have focused on the issues of irreversibility, learning, and option value. From these perspectives, the early abatement is considered as a sure price that should be paid in the face of unsure future losses due to climate change. In addition, the early abatement is also justifiable because it is less reversible relative to some impacts of climate change. In this regard, the early abatement is preferred to doing nothing because it leaves more flexible options open for future decisions. See for example: K. Kuntz-Duriseti, "Evaluating the Economic Value of the Precautionary Principle: Using Cost Benefit Analysis to Place a Value on Precaution", Environmental Science and Policy, Vol. 7, 2004, pp. 299-300; J.C.M. van den Bergh, "Optimal Climate Policy is a Utopia: From Quantitative to Qualitative Cost-Benefit Analysis", Ecological Economics, Vol. 48, 2004, pp. 385-393; and M. Ha-Duong, M.J. Grubb, and J.C. Hourcade, "Influence of Socioeconomic Inertia and Uncertainty on Optimal $\mathrm{CO}_{2}$-Emission Abatement”, Nature, Vol. 390, November 1997, pp. 270-273. 
After discussing the importance of early emissions reduction, a question arises as to who should bear the responsibility to take such an action. This is another hot topic in climate talks, which has motivated some countries to withdraw from the Kyoto Protocol. Hence, this paper will also be directed at discussing the question of why the burdens of emissions reduction should not be distributed equally. In this regard, this paper will present several reasons for differentiating common responsibility in dealing with the climate change issue.

After those discussions, this paper will be concluded by presenting some policy recommendations. Such recommendations are of high importance for the discussions about post-Kyoto commitments.

\section{Intergenerational Equity and Discount Rate}

According to the conventional application of cost-benefit analysis (CBA), a project is considered economically justifiable if its net value, namely the aggregate of costs and benefits, is greater than zero. Since these costs and benefits will occur over time, the idea of discounting those costs and benefits is introduced into the cost-benefit calculus. In this case, future outcomes will be valued from the standpoint of present time, in such a way that they will have a present equivalent value, referred to as the Present Value (PV). Consequently, the benefits of a policy, which are projected to occur in the future, will be discounted in order to express its present value, i.e. a value from the perspective of the current generation.

In the context of the economic appraisal of climate change, the use of discount rates works by reducing the future impacts of climate change. Hence, it could be argued that a discount rate placed on future impacts will ultimately reduce the severity of those impacts, and accordingly, it will also lessen the importance of taking early actions. The higher the discount rates, the lower the impacts of climate change, and the lower the optimal emissions abatement will be. This could, for example, be seen in Tol's study. Based on a sensitivity analysis conducted in this study, Tol has found that the choice of discount rate is the most important parameter in the economic appraisal on climate change. The discount rate is set at $10 \%$, the $\mathrm{MSC}^{11}$ is only about $6 \mathrm{US} \$ / \mathrm{tC}$. When the discount rate is reduced to $5 \%$, the MSC increases to $26 \mathrm{US} \$ / \mathrm{tC}$, and when it is eventually reduced to 0 (zero), the MSC increases up to $317 \mathrm{US} \$ / \mathrm{tC}^{12}$. Studies that estimate low MSCs, leading to the low current emissions reduction, typically use a discount rate of $3 \%$. In contrast, the high estimates of MSC have employed lower discount rates combined with longer periods of time.

Although there are several reasons to discount the impacts of climate change, the use of discount rates in the economic appraisal of climate change is, however, questionable. The proponents of discount rate have often argued that the use of the discount rate expresses actual private decisions. The discount rate, thus, reflects individuals' behaviour when they value events across periods because in reality, people tend to be impatient, as they prefer immedi-

\footnotetext{
${ }^{11}$ MSC stands for Marginal Social Cost. This is a method to find out how much damage will be created by emitting a ton of carbon or, alternatively, how much damage will be prevented from removing a ton of carbon from the atmosphere.

${ }^{12}$ R.S.J. Tol (1995), “The Marginal Costs of Greenhouse Gas Emissions”, The Energy Journal, Vol. 20(1), 1999, pp. 70-71.
} 
ate consumption to future consumption. ${ }^{13}$ In contrast, however, some authors have opposed the use of discount rate because, so they argue, applying individual decisions to a long-term policy such as climate policy is not always appropriate. Individuals may exhibit a certain level of impatience as they may think that they will not live forever; but this is certainly not the reason for the public policy makers to employ such individual impatience. This is especially true when one considers that unlike individuals' decisions, the benefits of social policy can be expected to transcend the lives of the decision makers. In this regard, Khanna and Chapman argue that there is no ethical basis to employ a certain degree of impatience in climate policy. According to the authors, public policy should be based on the sustainable interests of immortal society and, hence, should ignore the impatience that stems from the behaviour of mortal individuals. ${ }^{14}$

Economists have also argued that the use of discount rates is justified on the ground of diminishing marginal utility. In this case, because future generations are expected to be richer than the current generation, the discount rate may serve as an expression of diminishing marginal utility resulting from the increase of wealth over time. ${ }^{15}$ This argument is also problematic since if the current emissions level is allowed to continuously increase, the probability of catastrophic impacts also increases. Consequently, if there is an increasing probability of irreversible damage, it is questionable that future generations will certainly be richer than the current generation. In this regard, Gollier argues that uncertain future growth should induce the decision makers to select a smaller discount rate. According to the author, if the decision makers are prudent, uncertainty about future outcomes should lead them to care more about the future and, accordingly, take a precautionary measure as a premium to hedge against unpleasant outcomes in the future. In the context of discount rate, such a precautionary measure is manifested in the form of selecting a low discount rate when there is a possibility that the current development

${ }^{13}$ In economics, impatience, which places the interests of the current generation above those of future generations, is referred to as the pure time preference.

${ }^{14}$ See: N. Khanna and D. Chapman, "Time Preference, Abatement Costs, and International Climate Policy: An Appraisal of IPCC 1995", Contemporary Economic Policy, Vol. XIV, April 1996, p. 58. This opinion could also be found in Ramsey's opinion, a British economist whose formula has been widely used to calculate the social discount rate. Ramsey, as quoted by Chapman, et al., argues that the use of discount rate based on a pure time preference is "a practice which is ethically indefensible and arises merely from the weakness of the imagination". D. Chapman, V. Suri, and S.G. Hall, "Rolling Dice for the Future of the Planet", Contemporary Economic Policy, Vol. XIII, July 1995, p. 6.

${ }^{15}$ In Ramsey's formula, this factor is referred to as the growth discounting, namely a discount rate due to the expected economic growth resulting from the current development. Combining the growth discounting and the pure time preference, the Ramsey's formula is written as:

Social Rate of Time Preference (SRTP) $=\rho+\theta g$,

where:

$\rho$ is the rate of pure time preference (RPTP),

$\theta$ is the absolute value of the elasticity of marginal utility of income, and

$\mathrm{g}$ is the growth rate per capita consumption.

For information about the introduction of the use of Ramsey's formula in the economic appraisals of climate change, see: K.J. Arrow, et al., "Intertemporal Equity, Discounting, and Economic Efficiency", in: J.P. Bruce, H. Lee, and E.F. Haites (eds.), Climate Change 1995-Economic and Social Dimensions of Climate Change: Contribution of Working Group III to the Second Assessment Report of the Intergovernmental Panel on Climate Change (Cambridge University Press, 1996), pp. 130-132. 
will lead to catastrophic damage in the future. ${ }^{16}$

The use of discount rate has also been supported because it will allow the current generation to undertake development, the benefits of which will also benefit future generations. In this way, the current emissions do not only pass on damage to future generations, but also benefits, such as improved technology, which will enable future generations to better adapt to climate impacts. From this point of view, the transfer of welfare across generations is considered a form of compensation. Against such an opinion, Spash argues that the transfer of basic needs on the one hand and compensation on the other hand are rested on two separate ethical grounds. While basic transfer results from welfare distribution, compensation stems from a moral obligation not to deliberately inflict harm to others and to make reparation once this harm is created ${ }^{17}$ In addition, Spash also argues that if every individual has a right to be free from harm imposed by others, compensation is not a license to deliberately inflict harm to others. In this way, if harm cannot be prevented, actual-rather than merely potential-compensation is required.$^{18}$ The absence of a mechanism to carry out the actual intergenerational compensation, hence, can be used as a reason not to use the discount rate.

Finally, there is also an environmental consideration to use the discount rate. According to this opinion, if the use of high discount rates is also used to determine the level of investment, it has the potential to slow down the current development. In this way, natural resources will be less depleted under high discount rates than under low discount rates. ${ }^{19}$ Hence, the use of discount rates may also offer positive impacts to the environment. According to Broome, such an opinion rightly warns us about the danger to the environment that could result from fast economic growth. However, Broome continues, the danger is not created by a low interest rate, but mainly because there is a tendency to externalise environmental costs. Hence, if the impacts of development to the environment are seriously considered, the solution will be

${ }^{16}$ C. Gollier, “Discounting an Uncertain Future”, Journal of Public Economics, Vol. 85, 2002, pp. 153154. Applying lower a discount rate in the face of uncertainty is also given by Newell and Pizer. In this case, the authors argue that when facing two possible discount rates that are equally likely, the expected value of outcomes is closer to the result of lower discount rate, and not the result from the average of discount rate. This is because in the presence of uncertainty about the discount rate, what is being averaged is not the discount rate itself, but the discount factor. See: R. Newell and W. Pizer, "Discounting the Benefits of Climate Change Policies Using Uncertain Rates”, Resources, Issue 146, 2002, p. 17.

${ }^{17}$ In this regard, Spash makes an analogy with the government payments for the poor to provide support for their minimal standard of living. The author argues that such basic payments are not a reason to exclude the government from the obligation to compensate the poor (the beneficiaries of the basic payments) when they create projects that harm the poor. Similarly, intergenerational basic transfers are not a compensation to repair a deliberately created harm, such as GHG emissions. See: C.L. Spash, "Double $\mathrm{CO}_{2}$ and Beyond: Benefits, Costs and Compensation", Ecological Economics, Vol. 10, 1994, p. 32.

${ }^{18} \mathrm{Ibid}$., at 34 . It should be noted here that in the mainstream economic theory, efficiency is calculated according to the Kaldor-Hicks criterion. In traditional CBA, economists usually employ the KaldorHicks criterion, also referred to as the Potential Pareto, to compare the costs and benefits. According to this criterion, a proposed project will pass the CBA test so long as it is conceivable that, in principle, the gainers could compensate the losers, regardless of whether such compensation is actually paid. It means that in reality such compensation does not need to take place. See: D.W. Pearce, Economic Values and the Natural World (London: Earthscan, 1993), p. 48.

${ }^{19}$ D.W. Pearce and R.K. Turner, Economics of natural Resources and the Environment, $2^{\text {nd }}$ ed. (Baltimore: Jon Hopkins University Press; 1991), p. 224. 
to internalise the externality, and not to increase the discount rate. ${ }^{20}$

In sum, the use of high discount rates tends to discriminate future generations in two ways. On the one hand, it gives more value on projects that will create short-term benefits at the expense of future costs; and on the other hand, it decreases the urgency of policy that will create benefits for future generations. There are, thus, some good reasons to employ only low or even zero discount rates if there is a possibility that the current decisions will expose future generations to a non-zero probability of catastrophic events.

\section{Intragenerational Equity: Valuing Climate Change Impacts across Regions}

The economic appraisal of climate change will also be controversial when it comes to the estimation of non-marketed impacts. In calculating these impacts across regions, earlier economic studies have usually employed a direct aggregation, in which damage in each region is calculated in US Dollar, which will in turn be converted into a reduction in the Gross World Product (GWP). Take for example a study of Frankhauser, which has attempted to predict the economic impacts of climate change in the EU, USA, former Soviet Union countries, China, OECD, and the World. Sectors that are observed in this study include coastal defence, wetland loss, ecosystem loss, agriculture, forestry, fishery, energy, water, and people's migration. In terms of the reduction of GDP, China incurs the largest losses, namely as much as $4.7 \%$ of their national output. However, if damage is converted into US dollars, EU countries and the USA will experience the largest losses, respectively as much as US $\$ 63.6$ billion and US\$61 billion. The author directly sums up these dollar losses, of which result will also be indicated in the percentage of global output or GWP. Based on such a direct aggregation the total economic losses of the world will be $\$ 269.5$ billions or equal to $1.4 \%$ of global output. ${ }^{21}$

Tol has also tried to aggregate the economic impacts of climate change. In his study, the world is divided into 9 regions, namely OECD America (the USA and Canada), OECD-Europe, OECD Pasific (Japan, Australia, and New Zealand), Central and Eastern Europe and former of the USSR, the Middle East, Latin America, South and South East Asia, Centrally Planned Asia, and Africa. Countries expected to gain a $2.5^{\circ} \mathrm{C}$ warming are those in Central Europe, Eastern Europe and the former of the Soviet Union. These countries will benefit by $\$ 7.3$ billion, or equal to $0.3 \%$ of their GDP. On the other hand, regions that experience the most adverse impacts in terms of GDP losses are Africa and South and South East Asia, respectively as much as $8.7 \%$ and $8.6 \%$ reduction of their national output. However, in terms of dollar losses, OECD America will suffer the most, namely $\$ 74$ billion. Hence, when comparing between rich and poor countries (OECD and non-OECD countries), one will find that in terms of national output, non-OECD countries suffer more than OECD countries, namely $2.7 \%$ losses of their GDP compared to losses suffer by OECD countries as much as $1.6 \%$ of their GDP; while in terms of absolute losses, OECD countries will suffer higher losses, namely $\$ 189.5$ billion compared to $\$ 126.2$ billion

${ }^{20}$ J. Broome, Counting the Cost of Global Warming (Cambridge: the White Horse Press, 1992), pp. 101-102.

${ }^{21}$ S. Frankhauser, Valuing Climate Change: The Economics of the Greenhouse (London: Earthscan Publication, 1995), p. 55, tables 3.15 and 3.16. 
losses of non-OECD countries. By directly aggregating those losses, Tol estimates the total losses of climate change as much as $\$ 315.7$ billion, or around $1.9 \%$ of global output. ${ }^{22}$

Based on several studies, including the studies of Frankhauser and Tol mentioned above, the Second Assessment Report of the IPCC (referred to as the IPCC SAR) concludes that under the climate sensitivity of $2.5^{\circ} \mathrm{C}$ and bestguess estimates, the impacts of $\mathrm{CO}_{2}$ doubling ${ }^{23}$ for developed countries will be in the range of $1-1.5 \%$ of their GDP; while for developing countries the losses are in the range of $2-9 \%$ of their GDP. By directly aggregating these impacts, the IPCC concludes that the global impacts will be in the range of $1.5-2.0 \%$ of $\mathrm{GWP}^{24}$

Such a direct aggregation has, however, been severely criticized for various reasons, which are rooted from the uneven distribution of damage across regions. In this regard, developing countries, such as those located in Asia, are expected to experience the most severe loss from climate change, which could reach as much as $8 \%$ of their GDP, although they contribute only a tiny fraction of the current GHGs concentrations. There are good reasons to come to this prediction. First, geographically, developing countries are located in regions that are vulnerable to extreme weather events. Specifically, some developing countries are likely to experience extreme droughts; while others are prone to heavy precipitations. The impacts of these events may take place as the degradation of water supply and quality, the spread of weather-related diseases, or floods. In addition, these events may also damage the economy of developing countries, especially if the economy of those countries depends heavily on agriculture and natural resources. A few degrees of warming could create significant adverse impacts on agriculture and natural resources. It means that countries of which economy relies heavily on agriculture and natural resources will seriously be affected by global warming. Second, some countries, especially in Africa, are already experiencing severe droughts, which bring the people of these countries into serious problems, such as the lack of water supply and hunger. Considering the current environmental quality in those countries, one can hardly imagine that a warmer world will endow those countries with a climate that is more favourable compared to what they have been experiencing now. Thirdly, some developing countries are highly vulnerable the Sea Level Rise (SLR) because they are, wholly or partly, located in low regions (some countries are even small islands countries). A few centimetres increase of sea level may lead developing countries to a significant land loss. ${ }^{25}$ In addition, the same level of SLR may also inundate some highly

${ }^{22}$ R.S.J. Tol (1995), "The Damage Costs of Climate Change: Toward More Comprehensive Calculations", Environmental and Resource Economics, Vol. 5, 1995, p. 69, table 2.

${ }^{23} \mathrm{CO}_{2}$ doubling is a reference used in the majority of economic studies on the impacts of climate change. This reference is a period in which the concentration level of $\mathrm{CO}_{2}$ is considered to be twice as high as the level of pre-industrial era.

${ }^{24}$ D.W. Pearce, et al. (1995), "The Social Costs of Climate Change: Greenhouse Damage and the Benefits of Control", in: in: J.P. Bruce, H. Lee, and E.F. Haites (eds.), Climate Change 1995-Economic and Social Dimensions of Climate Change: Contribution of Working Group III to the Second Assessment Report of the Intergovernmental Panel on Climate Change (Cambridge University Press, 1996), p. 218.

${ }^{25}$ Nicholls and Mimura predict that a one-meter SLR will cause 20.7\% land loss in Bangladesh, $0.4 \%$ in India, $2.1 \%$ in Malaysia, and $12.1 \%$ in Vietnam, while Indonesia will suffer a $1.9 \%$ land loss only by 0.6 meter SLR. Some small islands countries will even lose far greater percentage of their land by a onemeter SLR. See: R.J. Nicholls and N. Mimura, "Regional Issues Raised by Sea-Level Rise and Their Policy 
populated regions of developing countries, exposing millions of people to the risks of severe floods. ${ }^{26}$ Fourthly, one could expect that developing countries lack capability to adapt to the impacts of climate change. Accordingly, these countries become more vulnerable to climate change compared to developed countries. ${ }^{27}$

These specific features of poorer countries will not be captured by the direct aggregation, because national output of these countries contributes only a tiny share to the global output. In this case, although the damage will be significant to the GDP of each poor country, it will be only a small fraction of GWP. Hence, as Sen argues, the focus on global output based on such a direct aggregation tends to be in conflict with the issue of justice and fairness across different regions, especially between developed and developing countries. ${ }^{28}$

Eventually, the impact of such an aggregation will be to lower the optimal emissions reduction level. This can be explained as follows. Let us consider Tol's calculation regarding the impacts of climate change on countries in South and Southeast Asia, which will be around US\$53.5 billions or $8.6 \%$ of their GDP. ${ }^{29}$ Based on this estimate, a question arises as to whether the OECD countries should reduce their emissions in order to prevent South and Southeast Asian countries from experiencing those impacts. To answer this question, the damage will be converted into the GDP of OECD countries. In this case, the impacts of US $\$ 53.5$ billions will be equal to only $0.45 \%$ of the GDP of OECD countries. Assuming the economic growth of OECD countries is as much as $2 \%$ per year, the impacts of US $\$ 53.5$ billions for those Asian countries correspond to only 2.7 months of growth in the OECD countries' economy. Since emissions reduction is costly, the $0.45 \%$ GDP loss, which is comparable to 2.7 months delay in OECD economic growth, can hardly recommend a meaningful reduction of GHG emissions in OECD countries..$^{30}$

In addition, the direct aggregation also implicitly assumes a linear utility function. For example, when converting the US $\$ 53.5$ billions loss suffered by South and Southeast Asian countries into the OECD's GDP, one is actually making an assumption that the same amount of money will create the same level of utility for the poor and the rich. In reality, the opposite seems to be case. Losing one dollar will reduce the well being of poor people more se-

Implications", in Climate Research, Vol. 11, 1998, pp. 11-14.

${ }^{26}$ Nicholls predicts that if no action is taken to curb emissions, the total numbers of people that will be flooded due to the rise of sea level in the 2080s are in the range of 2-50 million people per year. Such a large range of estimate is caused by the different scenarios on development path considered by the authors. A development path that is more environmentally friendly will give rise to the fewer numbers of people that will experience floods in the future. R.J. Nicholls, "Coastal Flooding and Wetland Loss in the $21^{\text {st }}$ Century: Changes under the SRES Climate and Socio-Economic Scenarios", Global Environmental Change, Vol. 14, 2004, p. 79.

${ }^{27}$ Similar reasons have also been given by Grubb. See: M. Grubb (1995), “Seeking Fair Weather: Ethics and the International Debate on Climate Change", International Affair, Vol. 71, No. 3, 1995, pp. 471472. See also: T. Banuri, et al., "Equity and Social Considerations", in: in: J.P. Bruce, H. Lee, and E.F. Haites (eds.), Climate Change 1995-Economic and Social Dimensions of Climate Change: Contribution of Working Group III to the Second Assessment Report of the Intergovernmental Panel on Climate Change (Cambridge University Press, 1996), p. 97.

${ }^{28}$ A. Sen, Rationality and Freedom (London: Belknap Press, 2002), pp. 544-545.

${ }^{29}$ The data is adopted from: D.W. Pearce, et al., op cit. note 24, at 205.

${ }^{30}$ Similar analogy is also given by Azar and Lindgren who convert the deaths of 1 million Ethiopians into the annual growth of global economy. See: C. Azar and K. Lindgren, "Catastrophic Events and Stochastic Cost-Benefit Analysis of Climate Change", Climatic Change, Vol. 56, 2003, pp. 246-247. 
verely than it reduces the well being of rich people.

The most controversial issue of the direct aggregation is related to the difference of the value of statistical life (VOSL) between developed countries and developing countries. ${ }^{31}$ Although it has been widely accepted by economists that different people may have different VOSLs, the application of different VOLSs between developed and developing countries in the economic appraisal of climate change is disputable. The first reason is that in the case of climate change, the policy makers are confronted with a situation when a decision of one country may affect the life of the people in other countries. Specifically, since developed countries are responsible for around $80 \%$ of total atmospheric GHG concentrations to date, a question emerges as to whether the economic appraisal should employ the VOSL of developed countries or developing countries. One possible answer to this question is by the use of the WTA, namely by directly asking people in developing countries as to how much they are willing to accept the compensation for the damage caused by climate change. However, in the absence of actual compensation and the lack of WTA studies in developing countries, this method is rather impractical. As an alternative, the IPCC SAR provides another method to calculate the VOSL of developing countries, namely by using the VOSL of developed countries as a point of reference, from which the VOSL of developing countries will be derived in proportion to their incomes relative to those of developed countries. ${ }^{32}$ Thus, if a country has income half of the income of a reference-developed country, its VOSL will be approximately half of that of the developed country. Based on this method, the VOSL of developing countries will be much lower than that of developed countries. For example, Frankhauser predicts that for the USA, the additional deaths due to climate change are 6,642 people, almost one-fifth of the increased mortality in China. However, since the author assigns the VOSL of the USA almost fifteen times higher than that of China, the monetised value for mortality in the USA is around $\$ 10$ billion, more than three times higher than that of China. ${ }^{33}$

Perhaps, one would argue that the different VOSLs above should not matter a great deal, since they are not intended to mean that the life of an American is worth the life of fifteen Chinese people. However, if the result of the different VOSLs is to reduce the developing countries' shares to the global damage estimates, such an argument is still objectionable. This leads to the second problem in the use of different VOSLs, namely political acceptability. In a politically sensitive issue such as climate change, in which developed countries are considered as the primary contributors, the use of different VOSLs will hardly be accepted by the representatives from developing countries. In fact, this issue has created immense resistant from developing countries during the approval process for the "Summary for Policymakers" of the WGIII of the IPCC SAR. ${ }^{34}$

${ }^{31}$ Theoretically, the VOSL is not an expression for the monetary unit attached to human lives. It is simply a method to reveal how much a person is willing to pay for a reduction of the risk of death (or alternatively, how much one is willing to accept for an increase of such a risk).

${ }^{32}$ See: D.W. Pearce, et al, op cit. note 24,at 197.

${ }^{33} \mathrm{~S}$. Frankhauser, op cit. note 21 , at 47.

${ }^{34}$ As quoted by Grubb, Kamal Nath, Indian environment minister during the negotiation for the IPCC SAR, argued: “...we unequivocally reject the theory that the monetary value of people's live around the world is different because the value imputed should be proportional to the disparate income levels of the potential victims...it is impossible for us to accept that which is not ethically justifiable, technically accurate 
In sum, direct aggregation and the different VOSLs will result in the low shares of developing countries to the global damage estimates, despite these shares are considerably high to their own GDP and the numbers of people in developing countries exposed to the risks of climate change are much higher than those in developed countries. Of course, one can still argue that economic analysis should only be concerned with the economic calculus, i.e. the benefit-cost ratio, and not with ethical considerations such as the equity issue. In addition, the economic losses potentially suffered by developing countries could be 'compensated' by large benefits resulting from GHG emissions in developed countries. However, in the absence of actual compensation, such a potential-Pareto optimality argument may be akin to saying that the potential damage suffered by poor countries is negligible simply because they are poor. ${ }^{35}$ Under this type of economic appraisal, the low level of emissions abatement, or even doing nothing, could be considered as the economically "optimal" policy, in spite of its potential to make the poor yet poorer.

In responding to various oppositions to the direct aggregation of the impacts across regions, some economists have improved their economic appraisals by taking into account the issue of equity more seriously. Such an improvement is proposed either because developing countries are considered to suffer the most from climate change, and hence, they should be given greater weights, ${ }^{36}$ or because without equity weights, summing up monetary impacts across regions implies a linear utility function, which could be considered inconsistent with the commonly known relationship between utility and income. ${ }^{37}$

Sterner and Azar are the first authors who have tried to formalize equity weights under the CBA approach. In their study, income is not equally distributed, and hence, the world is hypothetically divided into two types of countries, poor and rich. Each country is allowed to use their own VOSL, which means that the use of different VOSLs within country is not a problem. However, since the climate change issue implies a situation in which developed countries create damage not only to their own people but also to people in other countries, the damage suffered by people in poor countries should be weighted in such a way as to give proximity about welfare losses actually felt in these countries. Specifically, to give a monetary value for a small loss of global welfare due to a small increase of emissions, such a change in welfare is divided by the present value of marginal utility of income in rich countries. The reason for such a calculation is that economic appraisal is undertaken in accordance with the optimal emissions reduction done in rich countries. In this way, the damage in poor countries will be weighted at the level of damage suffered by rich countries, in order to express the same level of utility reduction suffered by poor countries. The value of weight factors is, thus, dependent on the ratio of income between rich and poor countries and the elasticity

or politically conducive to the interests of poor people as well as the global common good". See: M. Grubb, op cit. note 27 , at 471 .

${ }^{35}$ According to Grubb, this argument means that because poor or developing countries have little wealth, they have little to lose from climate change. See: Ibid.,at 470.

${ }^{36}$ D.W. Pearce, et al, 1995, op cit. note 24, at 205.

${ }^{37}$ S. Frankhauser, R.S.J. Tol, and D.W. Pearce, "The Aggregation of Climate Change Damages: A Welfare Theoretic Approach", Environmental and Resource Economics, Vol. 10, 1997, p. 251. 
of marginal utility of income. ${ }^{38}$

Based on this calculation, the weighted total damage estimate could reach $4.5 \%$ of the GWP, which is around three times higher than the estimate without weight factors. When the damage in poor countries is weighted by the inverse of income as indicated above, the marginal social cost of emission ranges from 39 to 590 US $\$ /$ tC. $^{39}$

Similar effort to calculate the weighted global damage has also been carried out by Frankhauser, Pearce and Tol. In their joint study, the authors provide three damage estimates according to three types of social welfare functions, namely the utilitarian welfare function, Nash-Bernoulli welfare function, and the Rawlsian welfare function. The total damage is defined as the sum of weighted damage from each country. The weight factors are some power of the ratio between averaged total income and the income of each country. ${ }^{40}$ According to the authors, if one employs the Nash-Bernoulli welfare function, which is equal to the utilitarian welfare function when the income elasticity of marginal utility is unity, ${ }^{41}$ the weight factor is the ratio between the averaged total income and the income of each country. In this way, the damage in developed countries is weighted by a factor less than unity, while the damage in developing countries by a factor more than unity. With this assumption, the global damage estimated by Frankhauser will increase from US $\$ 322$ billion (without equity weight) to US $\$ 405.2$ billion (weighted); while the damage estimated by Tol will increase from US $\$ 364.4$ billion to US $\$ 614.3$ billion. Based on those weighted damage estimates, it follows, thus, that the use of equity weights will increase the value of damage suffered by developing countries, which will eventually increase the global damage estimates.

\section{Applying a Common-but-Differentiated Responsibility in the Global Climate Policy}

Combined with a low discount rate, the weighted damage estimates will increase the optimal level of abatement. To illustrate this conclusion, let us take a look at another study of Tol that has compiled various economic appraisals of climate change impacts. ${ }^{42}$ Based on several criteria to assess the

${ }^{38}$ See: C. Azar and T. Sterner, "Discounting and Distributional Considerations in the Context of Global Warming", Ecological Economics, Vol. 19, 1996, pp. 178-179. More generally, the weights are also dependent on the (in)equality aversion. See mathematical proof of the weighted damage function in Appendix 1.

${ }^{39}$ Ibid.,at 181.

${ }^{40}$ S. Frankhauser, R.S.J. Tol, and D.W. Pearce, op cit. note 37, at 257-259. See also Appendix 1.

${ }^{41}$ Pearce argues that based on empirical studies, the value of income elasticity of marginal utility is in the range of $0.5-2$. Hence, a value of 1 is feasible. Similar opinion is also given by Tol, et al. See: D. Pearce, "The Social Cost of Carbon and Its Policy Implications", Oxford Review of Economic Policy, Vol. 19, No. 3, 2003, p. 373; also: R.S.J. Tol, et al., "Distributional Aspects of Climate Change Impacts”, Global Environmental Change, Vol. 14, 2004, p. 263.

${ }^{42}$ The author weighs the quality of the literatures based on five criteria, namely whether a study is peer-reviewed, whether it is based on independent impact assessment, whether it is based on dynamic climate change scenario, whether it is based on economic scenarios, and whether it estimates the MSC. Each of these criteria has scores from 5 to 0 . Furthermore, the author also weighs the age of the literature by 0.1 per year since 1990 . Without quality weights, the mean is US $\$ 129 / \mathrm{tC}$, with the $90^{\text {th }}$ and $95^{\text {th }}$ percentiles respectively are US $\$ 220 / \mathrm{tC}$ and US $\$ 635 / \mathrm{tC}$. If only peer-reviewed literatures are accounted, the mean and the $90^{\text {th }}$ percentile are US $\$ 50 / \mathrm{tC}$ and US $\$ 245 / \mathrm{tC}$. R.S.J. Tol, "The Marginal Damage Costs of Carbon Dioxide 
quality of those appraisals, Tol argues that the marginal cost of emissions (MSC) will not be greater than $50 \mathrm{US} \$ / \mathrm{tC} .{ }^{43}$

However, by using zero discount rate due to the pure time preference and employing equity weight to calculate the global damage, there is a good reason to deviate from Tol's prediction. Based on these assumptions and by focusing only on the peer-reviewed articles studied by Tol, I observe that the MSC will range from 23.5-590US\$/tC. It should be noted that 14 our of 15 estimates lie above 100US\$/tC. The mean of these estimates is $263 \mathrm{US} \$ / \mathrm{tC}$. These higher estimates of the MSC will obviously support early emissions reduction such as the one proposed by the Kyoto Protocol. ${ }^{44}$

In short, if equity, either as intergenerational or intragenerational equity, is seriously considered, economic appraisals will generate higher estimates of climate damage, which will, in turn, increase the importance of taking early emissions abatement. In other words, by concluding the importance of taking early actions against climate change, the previous two sections have explained that humans share a "common" responsibility to combat climate change and its adverse impacts. However, the importance of the early emissions abatement does not indicate the question of which countries should bear the responsibility to take such an action.

The answer for such a highly contentious question lies in the interpretation on the common but differentiated responsibility principle, as provided for in Article 3 of the 1992 UNFCCC. Unfortunately, despite recognizing the importance of the principle to guide any actions to prevent the so-called "dangerous interference of anthropogenic GHGs concentrations with the climate system", in which developed countries should play a leading role, the Convention does not explain on which basis such a differentiated responsibility should be implemented.

As science has increasingly supported the needs for an early emissions abatement, the issue of who should make such an early action becomes more important. Since the beginning of climate talks, such a question has been addressed by reference to the principle of common but differentiated responsibilities. In this regard, the UNFCCC notes that 'the largest share of historical and current global emissions of greenhouse gases has originated in developed countries, that per capita emissions in developing countries are still relatively low and that the share of global emissions originating in developing countries will grow to meet their social and development needs'.

The statement above indicates that the main differentiating factors of the common responsibility are historical and per capita emissions. However, these factors, in addition to the objective to stabilize the GHG concentration so as to prevent anthropogenic disruption to the climate system, have never been fully incorporated into the process of determining emission reduction targets. In this regard, Pardy has criticized the Kyoto Protocol on the grounds that the Protocol has chosen the wrong target (namely emission reduction, rather than emission target/limit). In Pardy's view, the Protocol has been based on a wrong basis that not all countries share responsibility, and that there is an

\footnotetext{
Emissions: An Assessment of the Uncertainties", Energy Policy, Vol. 33, 2005, p. 2070.

${ }^{43}$ Ibid.,at 2073.

${ }^{44}$ As mentioned in section 1, Nordhaus and Boyer estimate that the costs of meeting the Kyoto commitments are around $34.52 \mathrm{US} \$ / \mathrm{tC}$, much lower than the damage of climate change that is likely to occur if the current generation fails to significantly reduce their GHGs emissions.
} 
unequal share of responsibility for those who take the responsibility. In addition, so the author argues, the Protocol has been based on polluting pays, rather than polluter pays, because countries with the most contribution to past GHGs emissions have the least demanding target in absolute terms, and that the Protocol has failed to put the issue of climate change as a priority. ${ }^{45}$

As an alternative to the Protocol's common but differentiated principle, Pardy proposes a burden sharing based on per capita emissions. In this regard, Pardy argues that the burden sharing should first proceed from the calculation of the permissible global amount of GHG emissions. Once such a global limit of GHG emissions has been set, it will be divided by the world population to result in per capita emissions. These will be the emission limit of every person, which will then be multiplied by the population of each country to result in national emission limits. ${ }^{46}$ For example, assume that the global community has agreed to stabilize GHG concentrations at $450 \mathrm{ppm}$. According to the data of Corfee-Morlot and Höhne, such a concentration level will require the limit of GHG emissions by 2020 at $8.5-10.5$ GtC per year. ${ }^{47}$ Supposed that countries have also agreed to use the projected world population in 2020 as the baseline, one can calculate the required per capita emissions by dividing the annual global emissions in 2020 (e.g. $8.5 \mathrm{GtC}$ ) with the projected world population. Multiplying such per capita emissions with the projected population of a country, one may also find the country's emission limit. In this way, emission reduction will follow the so-called 'contraction and convergence' path, in which since each country bears an equal responsibility to keep its GHG emissions below its national limit, countries of which emissions exceed their national limits should reduce their emissions, while countries of which emissions are below their national limits still enjoy the rights to increase their emissions.

The concept of equal per-capita emissions stems from the ground that every person has an equal "right to pollute", and hence, to emit the same amount of GHGs. Such an opinion assumes that the atmospheric resource is a common resource, which should be equally allocated to each individual. From this perspective, it follows that the common atmospheric resource is currently still used unwisely and unevenly, because the resource is considered available freely, such that each country can exploit it for its own benefits regardless of the impacts of such unlimited exploitation on other parties. As a result, the current per capita emissions of developed countries are far above the global average of per capita emissions, while those of developing countries are below the global average. The concept of equal per-capita emissions accordingly argues that for each person shares equal entitlement of the common atmospheric resource, people in developed countries should significantly reduce their current excessive emissions, while people in developing countries are still allowed to emit more than their current emissions level. ${ }^{48}$

The proposal of an equal per capita emission limit has, however, been criticized for a number of reasons. First of all, the equal share of emissions

${ }^{45}$ B. Pardy,"The Kyoto Protocol: Bad News for the Global Environment”, Journal of Environmental Law and Practice, Vol. 14, 2004, pp. 29-36.

${ }^{46}$ Ibid., at 43-44.

${ }^{47}$ J. Corfee-Morlot and N. Höhne, "Climate Change: Long-term Targets and Short-term Commitments”, Global Environmental Change, Vol. 13,2003, p. 287.

${ }^{48}$ T. Banuri, et al., op cit. note 27, at 106. See also: M. Grubb, op cit. note 27, at 485. 
based on a per capita limit is considered to artificially benefit countries with large population. Indeed, one might argue that under the proposal of equal per capita emissions, countries with high GHG emissions, such as China, will appear to have low emissions in terms of per capita emissions due to their large population. In this regard, Posner and Sunstein argue that with the proposal of equal per capita emissions, "countries would be given an incentive - or at least no disincentive - to increase their populations". ${ }^{49}$ However, this critique fails to acknowledge that the proposals based on per capita emissions are usually given by referring to the population in a certain time, by which the world population of that time is used as a baseline to calculate per capita emissions ${ }^{50}$ With such a baseline, the incentive to increase the population, if any, will be significantly reduced, especially if the past population is employed as the baseline. In addition, the charge that per capita emissions will give an incentive for countries to increase its population is also problematic since it is based on a highly questionable assumption that the benefit of having a large population, i.e. the benefit of not having to reduce emissions due to low per capita emissions, will far outweigh the cost of having large population.

The second critique on the proposal of per capita emissions says that the proposal serves as a disguised transfer or redistribution of wealth from rich to poor countries. In addition, since per capita emission determines the emission limit of each country, it is doubtful if the redistribution of wealth stemming from per capita emission limit will eventually go to individuals according to their individual emissions. ${ }^{51}$ This critique is also problematic. For one thing, emission reduction is not a financial aid. In fact, if a country is obliged to provide payment or to buy emission credits from other countries, such a payment should be considered as compensation for past emissions and for failing to meet its reduction target, and not as a financial aid. ${ }^{52}$ For another, concerns that the transfer of payment as compensation for past emissions will not go directly to individuals because the payment is actually made through the government, does not mean that the payment is ethically flawed. In fact, this problem can be solved through, for instance, better, transparent, and participatory governance.

Another critique against the proposal of per capita emissions corresponds to the fact that developed countries, especially those with high per capita emissions, might be reluctant to undertake deep emissions cut because it involves huge amounts of money ${ }^{53}$ This critique, nevertheless, constitutes

${ }^{49}$ E. Posner and C. Sunstein, “Climate Change Justice”, Georgetown Law Journal, Vol. 96, 2008, at1609.

${ }^{50}$ For example, as refered by Gardiner, Jamieson and Singer have respectively use the population in 1990 and 2050 as the baseline for calculating per capita emissions. See: S. Gardiner, "Ethics and Global Climate Change", Ethics, Vol. 114, 2004, p. 584.

${ }^{51}$ E. Posnerand C. Sunstein, op cit. note 49, at 1608. See also: E. Posnerand D. Weisbach,Climate Change Justice(Princeton, NJ: Princeton University Press, 2010), pp.127-128.

${ }^{52}$ The Copenhagen Accord seems to agree not to consider fund mechanisms in climate change as a financial aid. In this regard, paragraph 8 of the accord urges to establish a "[s]caled up, new and additional, predictable and adequate funding". Furthermore, paragraph 1 of the Cancun Agreement states that equity and common but differentiated responsibilities should be used as guidance in formulating policies and actions that address mitigation, adaptation, finance, technology development and transfer, and capacitybuilding. See: FCCC/CP/2010/7/Add.1, Decision 1/CP.16.

${ }^{53}$ In this regard, Posner and Wisbach argue that 'insistence on per capita allocations would effectively doom any climate change agreement'. See: E. Posner and D. Weisbach, op cit. note 51, at 122. 
a pragmatic, but not an ethical, question. Apparently, such a question could be posed to any proposal of emission reduction, and hence could not be exclusively directed toward the proposal of per capita emissions. Moreover, the unwillingness to reduce emissions because doing so requires significant costs do not necessarily mean that a country with high past and current per capita emissions has an ethical ground to continue its unsustainable way of life that harms others and the planet. ${ }^{54}$

Despite its attractiveness, the proposal of per capita emissions above seems to ignore a very important aspect in mitigating GHG emissions, namely the issue of historical emissions. Hence, a more equitable proposal should be based not only on the notion of equal per-capita emissions, but also on different contributions to the increased atmospheric GHG concentrations. In this regard, it could be argued that the proposal of equal per capita emissions should be implemented on the basis of historical emissions. ${ }^{55}$

The idea behind historical emissions is that countries whose past emissions are more than an equal per capita allocation should have less than their equal per capita allocation of emission rights in the future, and vice versa for countries which have emitted less than their equal per capita entitlement. Based on this perspective, the current and future emissions reduction should be allocated according to each country's contribution to climate change.

For the first time, the needs to relate emission reduction target with past and per capita emissions appeared in the proposal of Brazil to the Ad Hoc Group on the Berlin Mandate, 31 July-7 August 1997. In this proposal, the Brazilian representatives stated:

"The principle of the common but differentiated responsibilities, between Annex I and non-Annex I Parties, arises from the acknowledgment by the Convention that the largest share of historical and current global emissions of greenhouse gas has originated in the developed countries. It is also acknowledged by the Convention that the per capita emissions in developing countries are still relatively low and that the share of global emissions originating in developing countries will grow to meet their social and development needs. A simple reading of this statement leads implicitly to the interpretation of the relative share of current and projected future emissions of the two groups of Parties as being a measure of the relative responsibility between the groups of Parties". ${ }^{56}$

Linking up the current and future responsibility with past GHGs emissions can be justified from several reasons. First, such an unequal responsibility is consistent with the polluter pays principle. In the context of climate change, this principle suggests that bygones are not bygones, so that each country bears a responsibility to reduce GHGs emissions in proportion to its past and current emissions. ${ }^{57}$

Second, as Neumayer argues, "science is on the side of historical

${ }^{54}$ An interesting analogy is given by Baer who argues "I may not like the high price of oil, but that doesn't mean I can steal it”. See: P. Baer, "Equity, Greenhouse Gas Emissions, and Global Common Resources", in S.H. Schneider, A. Rosencranz and J.O. Niles (eds), Climate Change Policy: A Survey (Washington DC: Island Press, 2002), p.404.

${ }^{55}$ See: FCCC/AGBM/1997/Misc.1/Add.3, 30/05/1997.

${ }^{56}$ E. Neumayer, "In defence of historical accountability for greenhouse gas emissions", Ecological Economics, Vol. 33, 2000, p. 186.

${ }^{57} \mathrm{~J}$. Ikeme, "Equity, Environmental Justice and Sustainability: Incomplete Approaches in Climate Change Politics", Global Environmental Change, Vol. 13, 2003, at 201. 
accountability".58 This is because, as implicitly recognized by Article 2 of the UNFCCC, climate change is a consequence of the increase of anthropogenic GHG concentrations in the atmosphere. Such concentrations are not the result of the emissions of any particular time. Instead, the increased GHG concentrations stem from emissions that have accumulated over a long period.

Third, differentiating responsibility in accordance with historical emissions could also be defended on the assumption that each person shares an equal opportunity to use atmospheric resource, regardless of when and where this person lives. Neumayer argues that ignoring historical emissions might mean "to privilege those who lived in the past in the developed countries and to discriminate against those who live in the present or will live in the future developing countries".59

Based on the discussions above, the differentiated responsibility could, thus, be interpreted as the allocation of emissions reduction on the basis of historical equal per capita emissions. Since more than 80 per cent of the current concentrations of GHGs have resulted from developed countries, ${ }^{60}$ it could be argued that developed countries owe a positive historical emission debt (HED) to developing countries. Hence, the current emissions reduction allocated to developed countries should be considered as compensation from countries with a positive HED to countries with a negative HED.

In practice, the extent of emissions reduction from each country will first depend on the agreement about the long-term target as the objective of the global policy on climate change. Such a target will then be used to derive the total emission reduction as a global commitment. Afterwards, there should be an agreement about a base year from which the historical emissions will be accounted for in order to calculate the HED of each country. Once the HED is established, there should also be an agreement about how long compensation from countries with a positive HED to those with negative HED will take place. It is from such a series of agreements that the current emissions reduction of each country will finally be defined. ${ }^{61}$

However, it should be noted here that Indonesia's position on the issue of burden sharing is rather ambiguous. On the one hand, Indonesia has put forward various proposals stating that emission reduction should be the responsibility of developed (Annex I) countries. For example, in the proposal concerning elements contained in the Bali Action Plan, Indonesia proposed that the goal of the Action Plan is "' $[\mathrm{t}] \mathrm{o}$ amend the target of Annex B of Kyoto Protocol in the second commitment period in aggregate and individually; Annex 1 Parties to the Kyoto Protocol should reduce emission in aggregate by at least 40\% from 1990 level by 2020 and 85\% from 1990 level by 2050 ". ${ }^{62}$ This proposal has been repeated in Indonesia's view on possible elements for amendments to the Kyoto Protocol proposed in April 2009. ${ }^{63}$ Furthermore, in

58E. Neumayer,op cit. note 56, at 187.

${ }^{59}$ Ibid., at 188.

${ }^{60}$ T. Banuri, et al., op cit. note 27, at 94 .

${ }^{61}$ A technical explanation for calculating the equal per capita emissions with historical responsibility is presented in Appendix 2.

${ }^{62}$ FCCC/AWGLCA/2009/MISC.6/Add.1, Ideas and Proposals on the Elements Contained in Paragraph 1 of the Bali Action Plan.

${ }^{63}$ In this regards, Indonesia proposed to ammend Art. 3 para. 1 of the Kyoto Protocol with the following paragraph:

"The Parties included in Annex I shall, individually or jointly, ensure that their aggregate anthro- 
June 2009 Indonesia also joined a group of developing countries that proposes emissions reduction conducted by developed (Annex I) countries should be based on historical emissions from the year 1850 to $2005 .{ }^{64}$

On the other hand, only few months after the submission of those proposals, Indonesia seemed to change its position by accepting the Copenhagen Accord and submitting its voluntary pledge of emission reduction. ${ }^{65}$ Subsequently, Indonesia has also submitted its pledge to cut emissions by 26-41 per cent from the BAU emission level. ${ }^{66}$ On this ground, one may argue that the issue of climate justice does not seem to matter a great deal for Indonesia.

pogenic carbon dioxide equivalent emissions of the greenhouse gases listed in Annex A do not exceed their assigned amounts, calculated pursuant to their quantified emission reduction commitments inscribed in Annex B and in accordance with the provisions of this Article, with a view to reducing their overall emissions of such gases by at least 18 per cent below 1990 levels in the second commitment period 2013 to 2017 and at least 40 percent below 1990 levels in the third commitment period 2018 to 2022".

See: FCCC/KP/AWG/2009/MISC.7, Views on Possible Elements for Amendments to the Kyoto Protocol Pursuant to Its Article 3.

${ }^{64}$ The proposal of this group reads as follows:

"The following paragraphs shall be added to Article 3 of the Protocol after paragraph 1:

1 bis The Parties included in Annex I shall reduce their aggregate anthropogenic carbon dioxide equivalent emissions of greenhouses gases listed in Annex A by at least 40 per cent below 1990 levels in 2020;

1 ter On the basis of the aggregate emission reduction specified in paragraph 1 bis, the Parties determined the individual quantified emission reductions commitments of Annex I Parties inscribed in Annex B for the second commitment period, by applying the principle of historical responsibility, from 1850 to 2005 ;

1 quater In the second quantified emission reduction commitment period, from 2013 to 2020, the assigned amount for each Party included in Annex I shall be equal to the percentage inscribed for it in Annex B of its aggregated anthropogenic carbon dioxide equivalent emissions of the greenhouse gases listed in Annex A in 1990, or the base year or period determined in accordance with paragraph 5 below, multiplied by eight."

See: FCCC/KP/CMP/2009/7, Proposal from Algeria, Benin, Brazil, Burkina Faso, Cameroon, Cape Verde, China, Congo, Democratic Republic of the Congo, El Salvador, Gambia, Ghana, India, Indonesia, Kenya, Liberia, Malawi, Malaysia, Mali, Mauritius, Mongolia, Morocco, Mozambique, Nigeria, Pakistan, Rwanda, Senegal, Seychelles, Sierra Leone, South Africa, Sri Lanka, Swaziland, Togo, Uganda, United Republic of Tanzania, Zambia and Zimbabwe for an amendment to the Kyoto Protocol.

${ }^{65}$ On 19 January 2010, Indonesia has submitted its commitment to the Secretariat. In a letter to the Executive Secretary of the UNFCCC, Mr.Witoelar, then the Minister of the Environment, stated "[f]rom the outset, I would like to underline Indonesia's support on the global effort to reduce the GHG concentration in the atmosphere. Please be reaffirmed that the Government of Indonesia fully endorses the Copenhagen Accord...". See: E-01/EC-NCCC/01/2010 (a formal letter of 19 January 2010 from Indonesia's Ministry of Environment to Yvo de Boer, the Executive Secretary of the UNFCCC).

${ }^{66}$ On 30 January 2011 another letter was also sent to the Secretariat reiterating Indonesia's association with the Copenhagen Accord, and declaring Indonesia's Nationally Appropriate Mitigation Actions (NAMAs) to a target of 26 per cent emission reduction by 2020. The reduction will be conducted through sustainable peat land management, reduction in rate of deforestation and land degradation, development of carbon sequestration projects in forestry and agriculture, promotion of energy efficiency, development of alternative and renewable energy sources, reduction in solid and liquid waste, and shifting to a lowemission transportation mode. See: E-03/EC-NCC/01/2010 (a formal letter of 30 January 2010 from Indonesia's Ministry of Environment to Yvo de Boer, the Executive Secretary of the UNFCCC).

It is worth mentioning that the commitment of 26 per cent emission reduction shall be achieved when the reduction is conducted alone. Further reduction up to 41 per cent is nevertheless declared when the reduction it is carried out with international support. It should also be mentioned here that the baseline used for such a reduction target is the projected emission level based on according to the business-asusual scenario. See: The Ministry of Environment of Indonesia, Indonesia Second National Communication 


\section{Conclusion}

The Kyoto Protocol has been considered economically inefficient. In this paper, I have tried to show that if the Protocol is to be criticized, it is because it fails to set up meaningful commitments about emission reduction. There are at least two factors that have undermined the importance of the Kyoto Protocol. First, commitments provided in the Protocol do not bear on any particular target that is intended to achieve. In my opinion, such a target could be better explained when climate change is truly considered a serious threat to humans and the environment. In this context, inter- and intragenerational equity play a very significant role to increase the value of the impacts of climate change. With such an increase in the estimated damage, the efforts to reduce the current GHGs emissions will also be better appreciated.

Second, the Kyoto Protocol also fails to relate the commitment of developed countries to reduce their emissions to the differentiated responsibility. It is unclear, for example, whether the differences in commitments of Annex B countries are assigned due to the differences in historical emissions of those countries.

In the context of climate change, the common but differentiated responsibility can be implemented in the form of unequal emission reductions, which are allocated on the basis of equal emissions right and historical emissions. However, in estimating the responsibility of each country, there are several issues that each country should agree upon. First, there should be a long-term target, from which the current global emissions reduction will be derived. Second, there should be a base year which can be used to calculate the level of HED of each country. Finally, there should also be an agreement as to how long countries with a positive HED will compensate other countries with a negative HED.

The issue of climate justice has actually become more important as countries failed to agree on the equitable and scientifically valid allocation of post-2012 commitments. The dying Kyoto Protocol and the failure to come to stronger commitments just show that countries are not serious enough in fighting climate change. Unfortunately, Indonesia as a developing country with vast population is also very ambiguous in promoting more just and valid emission reduction target.

\section{Bibliography}

\section{Books}

Alley, R.B. “Abrupt Climate Change”, Scientific American, November 2004, pp. 62-69.

Baer, P. "Equity, Greenhouse Gas Emissions, and Global Common Resources”. In: Schneider, S.H., A. Rosencranz, and J.O. Niles (eds). Climate Change Policy: A Survey, pp. 393-408. Washington DC: Island Press, 2002.

Banuri, T., et al. "Equity and Social Considerations". In: Bruce, J.P., H. Lee, and E.F. Haites (eds.). Climate Change 1995-Economic and Social Dimensions of Climate Change: Contribution of Working Group III to the Second Assessment Report of the Intergovernmental Panel on Climate Change,

(2010), at V-12. 
pp. 15-71. Cambridge University Press, 1996.

Broome, J. Counting the Cost of Global Warming. Cambridge: the White Horse Press, 1992.

Frankhauser, S. Valuing Climate Change: The Economics of the Greenhouse. London: Earthscan Publication, 1995.

Nordhaus, W.D. and J. Boyer. Warming the World: Economic Models of Global Warming. Cambridge, Ma: MIT Press, 2000.

Pearce, D.W., et al. "The Costs of Climate Change: Greenhouse Damage and the Benefits of Control", in: Bruce, J.P., H. Lee, and E.F. Haites (eds.). Climate Change 1995-Economic and Social Dimensions of Climate Change: Contribution of Working Group III to the Second Assessment Report of the Intergovernmental Panel on Climate Change, pp. 179-224. Cambridge University Press, 1996.Pearce, D.W. and R.K. Turner.Economics of natural Resources and the Environment, $2^{\text {nd }}$ ed. Baltimore: Jon Hopkins University Press, 1991.

Posner, E. and D. Weisbach.Climate Change Justice. Princeton, NJ: Princeton University Press, 2010.

Sen, A. Rationality and Freedom. London: Belknap Press, 2002.

Smith, J.B. et al. "Vulnerability to Climate Change and Reasons for Concern: A Synthesis", in: J.J. McCarthy, et al. (eds.), Climate Change 2001: Impacts, Adaptation, Vulnerability. Contribution of Working Group II to the Third Assessment Report of the Intergovernmental Panel on Climate Change, pp. 913-967. Cambridge: Cambridge University Press, 2001.

Watson, R. and the Core Writing Team (eds.), Climate Change 2001-Synthesis Report: Contribution of Working Groups I, II, and III to the Third Assessment Report of the Intergovernmental Panel on Climate Change. Cambridge: Cambridge University Press, 2001.

\section{Journals or Articles}

Arrow, K.J., et al. "Intertemporal Equity, Discounting, and Economic Efficiency". In: J.P. Bruce, H. Lee, and E.F. Haites (eds.), Climate Change 1995-EConomic and Social Dimensions of Climate Change: Contribution of Working Group III to the Second Assessment Report of the Intergovernmental Panel on Climate Change, pp. 124-144. Cambridge University Press, 1996.

Azar, C. "Weight Factors in Cost-Benefit Analysis of Climate Change", Environmental and Resource Economics, Vol. 13, 1999, pp. 249-268.Blanchard, 0 . and J.F. Perkaus, “Does the Bush Administration's Climate Policy Mean Climate Protection?", Energy Policy, Vol. 32, 2004, pp. 1993-1998.

Azar, C. and K. Lindgren. "Catastrophic Events and Stochastic Cost-Benefit Analysis of Climate Change", Climatic Change, Vol. 56, 2003, pp. 245255.

Azar, C. and T. Sterner. "Discounting and Distributional Considerations in the Context of Global Warming", Ecological Economics, Vol. 19, 1996, pp. 169-184.

Chapman, D., V. Suri, and S.G. Hall. "Rolling Dice for the Future of the Planet", Contemporary Economic Policy, Vol. XIII, July 1995, p. 1-9.

Corfee-Morlot, J. and N. Höhne, "Climate Change: Long-term Targets and Short-term Commitments", Global Environmental Change, Vol. 13, 2003, pp. 277-293.

Frankhauser, S., R.S.J. Tol, and D.W. Pearce. "The Aggregation of Climate Change Damages: A Welfare Theoretic Approach", Environmental and Resource Economics, Vol. 10, 1997, pp. 249-266.

Gardiner, S. "Ethics and Global Climate Change", Ethics, Vol. 114, 2004, pp. 555-600. 
Goklany, I.M. "Applying the Precautionary Principle to Global Warming”, Policy Study No. 158, Center for the Study of American Business, November 2000.

Gollier, C. "Discounting an Uncertain Future". Journal of Public Economics, Vol. 85, 2002, pp. 149-166.

Grubb, M. "Seeking Fair Weather: Ethics and the International Debate on Climate Change", International Affair, Vol. 71, No. 3, 1995, pp. 463-496.

Ha-Duong, M., M.J. Grubb, and J.C. Hourcade, "Influence of Socioeconomic Inertia and Uncertainty on Optimal $\mathrm{CO}_{2}$-Emission Abatement", Nature, Vol. 390, November 1997, pp. 270-273. Henson, R. The Rough Guide to Climate Change: the Symptoms, the Science, and the Solutions. London: Rough Guides, Ltd, 2006.

Ikeme, J. "Equity, Environmental Justice and Sustainability: Incomplete Approaches in Climate Change Politics", Global Environmental Change, Vol. 13, 2003, pp.195-206.

Khanna, N. and D. Chapman. "Time Preference, Abatement Costs, and International Climate Policy: An Appraisal of IPCC 1995". Contemporary Economic Policy, Vol. XIV, April 1996, pp 56-66.

Kuntz-Duriseti, K. "Evaluating the Economic Value of the Precautionary Principle: Using Cost Benefit Analysis to Place a Value on Precaution", Environmental Science and Policy, Vol. 7, 2004, pp. 291-301

Mendelsohn, R. "Perspective Paper 1.1", in B. Lomborg (ed.), Global Crises, Global Solutions, pp. 45-48. Cambridge: Cambridge University Press, 2004.

Neumayer, E. "In Defence of Historical Accountability for Greenhouse Gas Emissions", Ecological Economics, Vol. 33, 2000, pp. 185-192.

Newell, R. and W. Pizer."Discounting the Benefits of Climate Change Policies Using Uncertain Rates".Resources, Issue 146, 2002, p. 15-20.

Nicholls, R.J. "Coastal Flooding and Wetland Loss in the $21^{\text {st }}$ Century: Changes under the SRES Climate and Socio-Economic Scenarios", Global Environmental Change, Vol. 14, 2004, p. 69-86.

Nicholls, R.J. and N. Mimura. "Regional Issues Raised by Sea-Level Rise and Their Policy Implications", Climate Research, Vol. 11, 1998, pp. 5-18.

Pardy, B. "The Kyoto Protocol: Bad News for the Global Environment", Journal of Environmental Law and Practice, Vol. 14, 2004, pp. 27-45.

Pearce, D.W. Economic Values and the Natural World. London: Earthscan, 1993. . "The Social Cost of Carbon and Its Policy Implications", Oxford Review of Economic Policy, Vol. 19(3), 2003, pp. 362-384.

Posner, E. and C. Sunstein, "Climate Change Justice”, Georgetown Law Journal, Vol. 96, 2008, pp. 1565-1612.

Spash, C.L. "Double CO and Beyond: Benefits, Costs and Compensation". Ecological Economics, Vol. 10, 1994,p. 27-36.

Tol, R.S.J. "The Damage Costs of Climate Change: Toward More Comprehensive Calculations". Environmental and Resource Economics, Vol. 5, 1995, pp. 67-90.

"The Marginal Costs of Greenhouse Gas Emissions", The Energy Journal, Vol. 20(1), 1999, pp. 61-81.

. "The Marginal Damage Costs of Carbon Dioxide Emissions: An Assessment of the Uncertainties", Energy Policy, Vol. 33, 2005, pp. 2064-2074.

Tol, R.S.J., et al. "Distributional Aspects of Climate Change Impacts", Global Environmental Change, Vol. 14, 2004, pp. 259-272.

Van den Bergh, J.C.M. "Optimal Climate Policy is a Utopia: From Quantitative to Qualitative Cost-Benefit Analysis", Ecological Economics, Vol. 48, 2004, pp. 385-393. 


\section{Apendix 1. Weight Factors and the Aggregation of Global Damage}

Azar and Sterner assume the aggregate welfare function, $\mathrm{W}(t)$ as the sum of individuals' utility for a given level of income, $u(y(t))$, namely:

$W(t)=P_{r}(t) \cdot u\left(y_{r}(t)\right)+P_{p}(t) \cdot u\left(y_{p}(t)\right)$

Where:

- $W(t)$ is the aggregate welfare at time $\mathrm{t}$

- $\mathrm{y}_{\mathrm{r}}$ and $\mathrm{y}_{\mathrm{p}}$ are per capita income in rich and poor countries, respectively

- $\operatorname{Pr}(t)$ is population in rich countries at time $\mathrm{t}$

- $P_{p}(t)$ is population in poor countries at time $\mathrm{t}$

- $u\left(y_{r}(t)\right)$ is utility of rich countries corresponding to the level of income at time $t$

- $u\left(y_{p}(t)\right)$ is utility of poor countries corresponding to the level of income at time $\mathrm{t}$

The marginal change in welfare due to the small change in damage at time $t$, which results from a small change in $\mathrm{CO}_{2}$ emissions at present $\left(\mathrm{t}_{\mathrm{o}}\right)$, is given by the following equation:

$d W(t) / d m_{o}=-\left[\frac{d C_{r}(t)}{d m_{o}} \cdot u^{\prime}\left(y_{r}(t)\right)+\frac{d C_{p}(t)}{d m_{o}} \cdot u^{\prime}\left(y_{p}(t)\right)\right] \ldots$

where:

- $d W(t) / d m_{o}$ is the change of welfare at time $t$ due to the increase of emissions now

- $d C_{r}(t) / d m_{o}$ is the change of damage in rich countries at time $t$, due to the increase of emissions now

- $d C_{p}(t) / d m_{o}$ is the change of damage in poor countries at time $t$, due to the increase of emissions now

- $u^{\prime}\left(y_{r}(t)\right)$ is marginal utility of rich countries at time $\mathrm{t}$

- $u^{\prime}\left(y_{p}(t)\right)$ is marginal utility of poor countries at time $t$

To give a monetary value, equation (2) should be divided by the marginal utility of income in rich countries. Rich countries are chosen because at this moment the reduction is carried out in these countries. In addition, to give a present value, equation (2) should also be multiplied with a discount rate. In this way, we get:

$V_{C}(t)=\left[\frac{d C_{r}(t)}{d m_{o}} \cdot \frac{u^{\prime}\left(y_{r}(t)\right)}{u^{\prime}\left(y_{r}(0)\right)}+\frac{d C_{p}(t)}{d m_{o}} \cdot \frac{u^{\prime}\left(y_{p}(t)\right)}{u^{\prime}\left(y_{r}(0)\right)}\right] \cdot e^{-\rho t} \ldots$

Rewrite eq. (3), weget:

$V_{C}(t)=\frac{d C_{r}(t)}{d m_{o}} \cdot \frac{u^{\prime}\left(y_{r}(t)\right)}{u^{\prime}\left(y_{r}(0)\right)} \cdot e^{-\rho t}+\frac{u^{\prime}\left(y_{p}(0)\right)}{u^{\prime}\left(y_{r}(0)\right)}\left[\frac{d C_{p}(t)}{d m_{o}} \cdot \frac{u^{\prime}\left(y_{p}(t)\right)}{u^{\prime}\left(y_{p}(0)\right)}\right] \cdot e^{-\rho t}$

Where: 
- $V_{C}(t)$ is the present value of weighted MSC at time t due to current emissions

- $u^{\prime}\left(y_{r}(0)\right)$ is the present value of marginal utility of rich countries

- $e^{-\rho_{\mathrm{t}}}$ is the discount factor

In Eq. (4), the MSC of poor countries is weighted with a ratio between the present value of marginal utility in poor and rich countries (the factor in front of the bracket in the second term).

Azar, further explains the general equation for the weight factor. ${ }^{1}$ Now let us consider three welfare functions, identified by Frankhauser, et al., namely the utilitarian, Nash-Bernoulli, and Rawlsian-Maximin welfare functions. These functions can be written as:

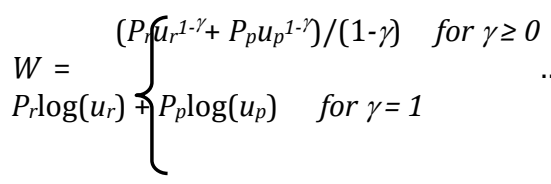

Where $\gamma$ is the degree of (in)equality aversion. If $\gamma=0$, we get a utilitarian welfare function; if $\gamma=1$, we get a Nash-Bernoulli welfare function; and if $\gamma=\infty$, we get a Rawlsian welfare function.

Now let us assume that the utility function follows the so-called constant relative risk aversion (CRRA) functions, namely:

$\frac{y^{1-k}}{(1-k)}$
$\log (y)$,$\left\{\begin{array}{l}\text { for } k \geq 0 \\ \text { for } k=1\end{array}\right.$

where $k$ is the elasticity of marginal utility of income, and $y$ is income.

Assume as well that in general, the weight factor $(\omega)$ is a ratio between the marginal utility of income in poor and rich countries multiplied by the ratio between the change of per capita welfare due to the change of utility in poor and rich countries. In this way, the weight factor is given by:

$\omega=\frac{u^{\prime}\left(y_{p}\right)}{u^{\prime \prime}\left(y_{r}\right)} \cdot \frac{d W / d u_{p}\left(y_{p}\right)}{d W / d u_{r}\left(y_{r}\right)} \cdot \frac{P_{r}}{P_{p}} \ldots$ (7)

Assuming the value of $k$ is greater than 0 and the welfare function is utilitarian, and differentiating eq. (5) and (6), eq. (7) can be rewritten as:

${ }^{1} \mathrm{C}$. Azar, "Weight Factors in Cost-Benefit Analysis of Climate Change", Environmental and Resource Economics, Vol. 13, 1999, pp. 255-256. 
$\omega=\frac{y_{p}^{-k}}{y_{r}^{-k}} \cdot \frac{P_{p} u_{p}^{-\gamma}}{P_{r} u_{r}^{-\gamma}} \cdot \frac{P_{r}}{P_{p}} \ldots .\left(7^{\prime}\right)$

or,

$\omega=\frac{y_{r}{ }^{k}}{y_{p}{ }^{k}} \cdot \frac{u_{r}{ }^{\gamma}}{u_{p}{ }^{\gamma}} \ldots .\left(7^{\prime \prime}\right)$

Inserting the value of $u$ in eq. (6) for $0 \leq k<1$

$\omega=\frac{y_{r}{ }^{k}}{y_{p}{ }^{k}} \cdot \frac{(1-k) y_{r}^{(1-k) \gamma}}{(1-k) y_{p}^{(1-k) \gamma}} \ldots .$.

$\omega=\left(y_{r} / y_{p}\right)^{k+\gamma-k \gamma}$

$\omega=\left(y_{r} / y_{p}\right)^{k+(1-k) \gamma}$

Eq. (8) implies that the weight factor depends not only on the degree of risk aversion (inequality aversion), $\gamma$, but also on the income elasticity of marginal utility, $k$. It is, hence, misleading to conclude that a high value of $\gamma$ will always lead to greater weight. From eq. (8"), it is clear that only if $k<1$ will $\gamma$ functions as inequality aversion. Once $k>1$, the higher the value of $\gamma$, the lower the weight will be. This means that if $k>1, \gamma$ functions as equality aversion.

Furthermore, if we assume a utilitarian welfare function $(\gamma=0)$ for eq. (8), the weight factor is given by:

$\omega=\left(y_{r} / y_{p}\right)^{k}$

This is the weight factor employed by Azar and Sterner, as presented in eq. (4).

If we assume a Nash-Bernoulli welfare function, where $\gamma=1$, the weight factor will simply be the income per capita of rich countries divided by the income per capita of poor countries.

However, under a Rawlsian-Maximin function, where $\gamma=\infty$, the weight factors for poor countries will be:

$\omega=\left(y_{r} / y_{p}\right)^{k+(1-k) \infty}$ 
From eq. (10), we see that as long as $\mathrm{k}<1$, the Rawlsian-Maximin welfare function will give poor regions an infinite weight. It is for this reason that Azar argues that under the RawlsianMaximin function, the optimal emission reduction for rich countries will be $100 \% .^{2}$ This result is quite different from the results of Frankhauser, et al., which show that the RawlsianMaximin will result in the lowest damage estimates compared to the two other welfare functions. ${ }^{3}$

\section{Appendix 2. Per Capita Emissions with Historical Responsibility ${ }^{4}$}

To find out the emission target allocated for country $i$ for each year $t$ over a future time of commitments $T,(t=1, \ldots T)$, one first should specify the historical emission debt of this country. Here, the HED is the sum of emissions that are still remaining in the atmosphere minus the total per capita emissions of this country, calculated from the base year $s$ until the end of accounting $e$. The HED can, thus, be written as:

$$
H E D_{i}=\sum_{j=s}^{e}\left[y_{i}(j)-\left(\frac{\operatorname{Pop}_{i}(j)}{\operatorname{Pop}_{w}(j)} \cdot y_{w}(j)\right)\right]
$$

where,

- $\quad \mathrm{HED}_{i}$ is the Historical Emission Debt of country $i$.

- $\quad s$ is the start year from which the historical emission will be calculated

- $\quad j$ is the year where emissions of country $i$ still exist in the atmosphere. In order to express the accumulation of emissions, the base year sis determined as the year $j$, in which emissions are still remaining in the atmosphere.

- $\quad e$ is the end year of calculating the HED

- $\frac{\operatorname{Pop}_{i}(j)}{\operatorname{Pop}_{w}(j)}$ is a ratio between the population of country $i$ in the start year and the population of the world in the start year

- $\quad y_{i}(j)$ is the country $i$ 's emission in year $j$

- $\quad y_{w}(j)$ is the world's emission in year $j$

When the value of HED has been determined, developed (countries with a positive HED) and developing (countries with a negative HED) should agree on how long the compensation from developed to developing countries will take place. Assuming that the agreed period of compensation is $\mathrm{N}$, the amount of compensation can be written:

$$
C_{i}^{n}=1 / N \cdot H_{E D} D_{i}^{n}(n=1, \ldots, N)
$$

Where,

IIbid., p. 262. 269.

${ }^{3}$ S. Frankhauser, R.S.J. Tol, and D.W. Pearce, 1997, op cit. note Error! Bookmark not defined., at 258-

${ }^{4}$ Adopted from: E. Neumayer, op cit. note Error! Bookmark not defined., at 186-187. 
- $\quad C_{i}^{n}$ is the compensation target of country $i$

- $\quad N$ is the number of years during which the compensation takes place

- $\quad H E D_{i}^{n}$ is the historical debt of country $i$ that is still remaining in the atmosphere in year $n$

Finally, equal allocation per capita basis with historical responsibility can be explained according to the following formula, namely:

$$
x_{i}^{t}=\frac{\operatorname{Pop}_{i}^{b}}{\operatorname{Pop}_{w}^{b}} \cdot w^{t}-C_{i}^{n}
$$

where,

- $\quad x_{i}^{t}$ is the emission of country $i$ at time $t$

- $\quad \frac{P o p_{i}^{b}}{P o p_{w}^{b}}$ is the ratio between the population of countries $i$ and that of the world.

- $w^{t}$ is the world's emission at year $\mathrm{t}$

- $\quad C_{i}^{n}$ is the compensation target of country $i$ in year $n$, the yearwhen emissions are still remaining in the atmosphere. 